\title{
Burnout syndrome in neurological nursing
}

Z. Slezáková1,2, G. Vörösová', G. Mičinová

Original Articles

${ }^{1}$ Constantine the Philosopher University in Nitra, Faculty of Social Sciences and Health Care, Department of Nursing, Kraskova no. 1, 94974 Nitra, Slovak Republic

${ }^{2}$ St. Elizabeth University of Health and Social Work in Bratislava, Slovak Republic

\section{Correspondence to:}

Constantine the Philosopher University in Nitra, Faculty of Social Sciences and Health Care, Department of Nursing, Kraskova no. 1, 94974 Nitra, Slovak Republic;

e-mail: gvorosova@ukf.sk, zuzana.slezakova@health.gov.sk, zlezakova@ukf.sk, tel. no. +421904247049

Submitted: 7.5.2016

Revised: 25.6.2016

Accepted: 18.8 .2016

\section{Reviewers:}

E. Grey

Department of Social Work, St. Elizabeth University of Health and Social Work in Bratislava, Slovak Republic

V. Tkac

Charles University in Prague, Faculty of Law, Czech Republic

\section{Key words:}

burnout, Maslach Burnout Inventory - MBI, Nursing, Neurological Nursing, Oncological Nursing

CSWHI 2016; 7(2): 36-46 @ 2016 Clinical Social Work and Health Intervention

\section{Abstract:}

Objective: To ascertain the incidence of burnout syndrome in Nurses working in Neurological Nursing. Burnout Syndrome (SV) often occurs in Neurological Nursing, where the Nurses are in circumstances associated with suffering and death. Design: For the diagnosis of burnout syndrome we used the Maslach Burnout Inventory (MBI). Respondents consisted of Nurses $n=120$ working at the Neurological Department, in a hospital and ambulances belonging to those wards in Slovakia. Results: In our study, out of $n=120$ Nurses working at the Departments of Oncology 50, 83\% showed high levels of burnout in their degree of emotional burnout (EE). We found that the age of Nurses has an impact on the formation of burnout syndrome: where the age range was 31-40 years old, $62.16 \%$ showed high degrees of burnout in the degree of depersonalization (DP); $64.86 \%$ showed a medium degree in the degree of personal satisfaction (PAT). The relation between seniority in 
neurological care and burnout syndrome is not confirmed. However the relation between the total length of practice and the degree of burnout is confirmed. Concusions: Based on the findings, the management of Neurological and Oncological Nursing it can be recommended that more focus be placed on programs of preventive measures in the field of burnout among Nurses.

\section{Introduction}

The concept of the term "burnout" begins to appear for the first time in the 1970s. Herbert Freudenberger, who defined this term in 1974 is considered its Founder. Several authors clarified the definition, for example Edelwich, Brodsky (1980), Pines, Aronson (1981) Sarros, Densten (1989), Glozier (2002), Kraft (2006), as a feeling of fatigue and exhaustion, or a whole range of physical challenges from recurring headaches, respiratory distress through gastrointestinal problems, to depression and insomnia. It not only affects psychosomatic areas, but also the realms of Psychology and the behavioral sphere. Many authors in our study looked at burnout syndrome among the helping professions, e.g. Venglářová et al (2011), Vorlíček, Abrahámová, Vorlíčková et al (2012), Klimeková (2007), Eliášová (2010), Sorková and Zvaríková (2003), Heftyová (2002) and others. Aronson, et al (1985) differentiates between burnout syndrome and exhaustion. Even though these phenomena are similar they have different causes. The cause of exhaustion may lay in any prolonged stress (physical, mental, emotional), but it does not mean that the situation of a completely exhausted person cannot be based on a sudden change in his life, e.g. as a result of some current trauma. The typical symptom of exhaustion is that the negative aspects of a person are permanently in predominance than positive aspects. The person feels unappreciated and worthless. The burnout syndrome is also manifested by physical, emotional and mental fatigue, but everything is due to chronic stress which is associated with long-term commitment toward other people. A 'Helper', as described by Andrasiova (2006), is a syndrome formed by combining characteristic personality traits from social assistance and rigid life form at the expense of one's personal development.

A 'Helper, is highly oriented to the ideal, self and needs and capacity to receive help.

This ideal, however, can only be sustained with a denial of reality, and in time, will necessarily result in feelings of frustration, failure and subsequent burnout. Burnout can be understood as a complete fatigue of one's work which was previously perceived positively, but today only gives a sense of non-satisfaction and excessive sacrifice that comes to nothing. The work of a Nurse in Oncology Nursing is very demanding in terms of mental composure and professionalism. As reported by Hnatova and Kovalcikova (2010), a Nurse is in constant confrontation with suffering, dying and death and is one of the main causes of burnout. Patient care, especially in the last stage of life is indeed stressful for Nurses, but may bring some sense of satisfaction for them. 


\section{Materials and methods}

We used the standardized Maslach Burnout Inventory (MBI) Questionnaire to map the neurological impact on Nurses of their nursing practice; its impact as well as prevention of the occurrence of burnout syndrome in the conditions of Neurological Nurses in Slovakia. The sample consisted of $n=120$ respondents $(92.50 \%$ women and $7.50 \%$ men): the age of Nurses under 30 years of age $n=27(22.50 \%) ; 31-40$ years of age $n=37(30.83 \%) ; 41-50$ years of age $\mathrm{n}=31(25.83 \%) ; 51$ years old and older $\mathrm{n}=25$ (20.84\%); by education, $25 \%$ secondary education, $15.83 \%$ secondary vocational education, 38.34\% Bachelor (Bc.) Degree and 20.83\% Master Degree (Mgr.); from these, 29.17\% with Specialization and Certification studies. The length of nursing practice under 10 years $n=61(50.83 \%) ; 11-20$ years $\mathrm{n}=50(41.17 \%) ; 21-30$ years $\mathrm{n}=5(4.17 \%)$ and 31 years and older $n=4(3.33 \%)$. The sample consisted of Nurses working at the Inpatient Department of Neurology, Clinical and Radiation Oncology, Primary Care Clinics belonging to those Departments in Slovakia $n=58(48.33 \%)$ in Hospitals with Health Centers, or Teaching Hospitals, $n=62(51.67 \%)$ from specialized institutes.

For the diagnosis of burnout syndrome, we used the Maslach Burnout Inventory (MBI) whose authors are Christina Maslach and Susan Jackson (1981,1986). The MBI has been modified three times; the last correction in 1996; and at present, is used in this form (Maslach, Jackson, Leiter 1996; Bakker, Demerouti, Schaufeli 2002; Bartošíková 2006).

We found several studies in the available databases in which MBI was verified in the helping professions, for example, Kalliath et al (2000), Gil-Monte (2005), Aguayo et al (2011), Chirkowska-Smolak, Kleka (2011), Córdoba et al (2011), Sabbah et al (2012), Mészáros et al (2014),
Figueiredo-Ferraz, Gil-Monte, Grau-Alberola (2013), Dyrbye et al (2013), Chen et al (2014) and others. The MBI Questionnaire used is according to Kebza and Šolcová (2003). Several studies have verified it in terms of psychometric properties including Leiter, Schaufeli (1996), Schutte et al ( 2000), Rothmann, Vuuren (2002), Rothmann, Malan (2003), Campbell, Rothmann (2005), Córdoba et al (2011), Aguayo et al (2011) where many other parameters for EE (Emotional exhaustion-emotional burnout) moved the alpha coefficient from 0.81 0.92 for DP (Depersonalization) 0.57-0.82 and PA (Personal accomplishment-personal satisfaction) from 0,50-0,86. According to Maslach, Jackson (1981,1986), Maslach, Jackson, Leiter (1996), Venglářova (2011), Aguayo et al (2011), Chen et al (2014) the MBI Questionnaire made up of 22 questions is divided by different dimensions into three subscales. The first subscale is made up of nine questions and is focused on emotional burnout (EE) characterized by emotional tension and inability to meet requirements. The second subscale consists of five questions that assess depersonalization (DP), the feeling of a decrease of competence and poor performance. The third subscale contains eight questions focused on personal satisfaction or job satisfaction (PA); characterized by numbness, impersonality, and negativism. Since SV is a complicated psychological construct, the various subscales are combined in order to affect as many areas as possible. The total score is not measured (Table 1).

In a statistical analysis, we used the chisquare test of independence for the pivot table. According to Chráska (2007), this test of significance can be utilized when deciding whether there is a correlation between the two phenomena. We are reviewing the test by comparing values calculated and values from the table. Values from the table are 
Table 1 Spot evaluation of MBI subscales

\begin{tabular}{|c|c|c|c|}
\hline \multirow{2}{*}{$\begin{array}{c}\text { FACTOR } \\
(\text { dimension })\end{array}$} & low & medium & high \\
\cline { 2 - 4 } & $0-16$ & $17-26$ & 27 and more \\
\hline EE & $0-6$ & $7-12$ & 13 and more \\
\hline DP & 39 and more & $38-32$ & $0-31$ \\
\hline
\end{tabular}

seen thanks to the significance level $(\alpha)$ and the degree of freedom (f). Significance level $(\alpha)$ was at 0.05 .

Degree of freedom (f) is calculated based on data from the pivot Table. It applies that $\mathrm{f}=(\mathrm{r}-1)(\mathrm{s}-1)$, where (r) is the number of rows and (s) is the number of columns of the pivot Table.

\section{Results}

Based on statistical analysis, we present the data obtained in the individual components of MBI (Table $2 \boldsymbol{\&} 3$ ), comparison by years of experience in the Oncology Department and overall experience (Table 4,5 \& 6), by type of workplace (Table $7 \& 8$ ) and the age of Nurses (Table $9 \& \mathbf{1 0}$ ).

\section{Discussion}

Aiken et al (2001) reported that as a result of their study between 1998-1999 on a sample 43,329 Nurses who where investigated using MBI, they realized that the rate of burnout in the emotional area (from Pennsylvania 13 471/43.2\%; from Canada 17 450/36\%; from England 5 006/36.2\%; from Scotland 4 721/29.1\%; from Germany $2681 / 15.2 \%$ ). In our study of n-120 Nurses working at the Department of Neurology, we showed a high rate of burnout in the Emotional Burnout Dimension (EE) - 50.83\%. We agree with Mr. Kmet (2010) who states that the risk of emotional exhaustion and feelings of inner emptiness arise if the Nurse treats eight patients instead of four patients; the risk of $\mathbf{S V}$ increases by $23 \%$ allocated to each additional patient. The Nurses are exposed to excessive physical and mental stress. Similarly our findings compared (Table 5) with the Spanish Study, showed that in the Intensive Care Departments (Iglesias et al 2010, In Preventing...2014), Nurses had the highest level of burnout in Emotional Burnout Level; a medium level in depersonalization; and a low level of personal satisfaction. The study of Catalana et al (1996 In Balbay et al 2011), which compared the level of burnout among the oncology professionals and personnel working with HIV positive people: the oncology staff was found with a high level of burnout $4 \%$, which was although less $4 \%$ of the working staff with HIV positive patients indicates a high tendency for oncology center professionals for the formation of burnout syndrome.

We found that the type of health facility can affect the rate of burnout among Nurses (Table7 \& 8) where there is confirmed a relationship between the monitored facility and the rate of burnout in the degree of emotional burnout; $33.33 \%$ of Nurses working in specialized institutions vs. $17.50 \%$ in a Hospital or University Hospital. The length of service is an important factor in the burnout process. According to Aronsona 
Table 2 Comparison of the degree of burnout in various dimensions of MBI

\begin{tabular}{|c|c|c|c|c|c|c|}
\hline \multirow{2}{*}{$\begin{array}{c}\text { Degree of } \\
\text { burnout }\end{array}$} & \multicolumn{2}{|c|}{ EE } & \multicolumn{2}{c|}{ DP } & \multicolumn{2}{c|}{ PA } \\
\cline { 2 - 7 } & $\mathrm{n}$ & $\%$ & $\mathrm{n}$ & $\%$ & $\mathrm{n}$ & $\%$ \\
\hline low & 25 & 20.8 & 25 & 20.83 & 41 & 34.17 \\
\hline medium & 34 & 28.33 & 44 & 36.67 & 58 & 48.33 \\
\hline high & 61 & 50.83 & 51 & 42.50 & 21 & 17.50 \\
\hline Total & 120 & 100 & 120 & 100 & 120 & 100 \\
\hline
\end{tabular}

Table 3 Statistical dependence between dimensions MBI

\begin{tabular}{|c|c|c|c|c|}
\hline Dimension & $\chi^{2}{ }_{\text {calc.. }}$ & $\mathbf{f}$ & $\chi^{2}{ }_{\text {tab.0,05 }}$ & Evaluation \\
\hline EE, DP, PA & 31.587 & 4 & 9.488 & $\chi_{\text {vyp. }}^{2} \boldsymbol{\chi}_{\text {tab. } 0,05}^{2}$ \\
\hline
\end{tabular}

Table 4 Experience in Neurological Nursing in relation with dimension MBI

\begin{tabular}{|c|c|c|c|c|c|c|c|c|c|c|c|}
\hline \multirow{2}{*}{\multicolumn{2}{|c|}{$\begin{array}{c}\text { Years of } \\
\text { Experience }\end{array}$}} & \multicolumn{2}{|c|}{ Under $10 \mathrm{r}$. } & \multicolumn{2}{|c|}{$11-20$ r. } & \multicolumn{2}{|c|}{$21-30$ r. } & \multicolumn{2}{|c|}{$31+$} & \multicolumn{2}{|c|}{ Total } \\
\hline & & $\mathbf{n}$ & $\%$ & $\mathbf{n}$ & $\%$ & $\mathbf{n}$ & $\%$ & $\mathbf{n}$ & $\%$ & n & $\%$ \\
\hline \multirow{3}{*}{$\mathbf{E E}$} & Low & 16 & 13.33 & 9 & 7.50 & 0 & 0.00 & 0 & 0.00 & 25 & 20.83 \\
\hline & Medium & 19 & 15.83 & 14 & 11.67 & 1 & 0.83 & 0 & 0.00 & 34 & 28.33 \\
\hline & High & 26 & 21.67 & 27 & 22.50 & 4 & 3.33 & 4 & 3.33 & 61 & 50.83 \\
\hline \multirow{3}{*}{ DP } & Low & 13 & 10.83 & 11 & 9.17 & 1 & 0.83 & 0 & 0.00 & 25 & 20,83 \\
\hline & Medium & 24 & 20.00 & 14 & 11.67 & 2 & 1.67 & 0 & 0.00 & 40 & 33.34 \\
\hline & High & 24 & 20.00 & 25 & 20.83 & 2 & 1.67 & 4 & 3.33 & 55 & 45.83 \\
\hline \multirow{3}{*}{ PA } & Low & 5 & 4.17 & 14 & 11.67 & 0 & 0.00 & 4 & 3.33 & 23 & 19.17 \\
\hline & Medium & 31 & 25.83 & 20 & 16.67 & 3 & 2.50 & 0 & 0.00 & 54 & 45.00 \\
\hline & High & 25 & 20.83 & 16 & 13.33 & 2 & 1.67 & 0 & 0.00 & 43 & 35.83 \\
\hline
\end{tabular}

et al (1985), in the care of people with seniority there is a proportional decrease in the sense of satisfaction from their work. Dimunová a Nagyová (2012) examined the effect of the length of service in their work on SV in a cohort of 844 Nurses. In the final assessment, they did not confirm the statistical significance of the relationship.
Analysis of the various dimensions of the relationship in the practice in the Neurology Department shows in Table 4 where we see the highest rate of burnout in Emotional Burnout: $22.50 \%$ indicates Nurses with 11 20 years of service; in Table 5 we see that there is no relationship between the length of experience in Neurological Nursing and 
Table 5 The statistical calculation in dependence of length of work in Neurological Nursing and MBI

\begin{tabular}{|c|c|c|c|c|}
\hline dimensions & $\chi_{\text {calc. }}^{2}$ & $\mathbf{f}$ & $\chi_{\text {tab.0,05 }}^{2^{2}}$ & Evaluation \\
\hline EE & 7.995 & 6 & 12.592 & $\chi^{2}{ }_{\text {vyp. }}<\chi_{\text {tab. } 0.05}^{2}$ \\
\hline DP & 8.921 & 6 & 12.592 & $\chi^{2}{ }_{\text {vyp. }}<\chi_{\text {tab. } 0.05}^{2}$ \\
\hline PA & 15.433 & 6 & 12.592 & $\chi_{\text {vyp. }}^{2}>\chi_{\text {tab. } 0.05}^{2}$ \\
\hline
\end{tabular}

Table 6 The statistical correlation between total length of nursing practice and MBI

\begin{tabular}{|c|c|c|c|c|}
\hline dimension & $\chi^{{ }^{2}}$ vyp. & $\mathbf{f}$ & $\chi_{\text {tab.0,05 }}^{2}$ & Evaluation \\
\hline EE & 13.57 & 6 & 12.592 & $\chi_{\text {vyp. }}^{2}>\chi_{\text {tab. } 0.05}^{2}$ \\
\hline DP & 18.100 & 6 & 12.592 & $\chi_{\text {vyp. }}^{2}>\chi_{\text {tab. } 0.05}^{2}$ \\
\hline PA & 13.295 & 6 & 12.592 & $\chi_{\text {vyp. }}^{2}>\chi_{\text {tab. } 0.05}^{2}$ \\
\hline
\end{tabular}

Table 7 Comparison by type of workplace

\begin{tabular}{|c|c|c|c|c|c|c|c|}
\hline \multirow{2}{*}{\multicolumn{2}{|c|}{ Type of institution }} & \multicolumn{2}{|c|}{$\begin{array}{l}\text { Hospital with Out } \\
\text { Patient Clinic/ } \\
\text { University Hospital }\end{array}$} & \multicolumn{2}{|c|}{$\begin{array}{l}\text { Specialized } \\
\text { Institutions }\end{array}$} & \multicolumn{2}{|c|}{ Total } \\
\hline & & $\mathbf{n}$ & $\%$ & $\mathbf{n}$ & $\%$ & $\mathbf{n}$ & $\%$ \\
\hline \multirow{3}{*}{$\mathbf{E E}$} & Low & 15 & 12.50 & 10 & 8.33 & 25 & 20.83 \\
\hline & Medium & 22 & 18.33 & 12 & 10.00 & 34 & 28.33 \\
\hline & High & 21 & 17.50 & 40 & 33.33 & 61 & 50.83 \\
\hline \multirow{3}{*}{ DP } & Low & 15 & 12.50 & 10 & 8.33 & 25 & 20.83 \\
\hline & Medium & 24 & 20.00 & 20 & 16.67 & 44 & 36.67 \\
\hline & High & 19 & 15.83 & 32 & 26.67 & 51 & 42.50 \\
\hline \multirow{3}{*}{ PA } & Low & 23 & 19.17 & 18 & 15.00 & 41 & 34.17 \\
\hline & Medium & 28 & 23.33 & 30 & 25.00 & 58 & 48.33 \\
\hline & High & 7 & 5.83 & 14 & 11.67 & 21 & 17.50 \\
\hline
\end{tabular}

degree of burnout in dimensional burnout (EE) and depersonalization (DP).

The question in the study on the degree of personal satisfaction (PA) confirmed this relationship. We confirmed this relationship with the study by Iglesias et al (2010) which states that respondents with a seniority of 10 years are more prone to emotional burnout and depersonalization and personal dissatisfaction (PA). We can say that if the Sister has over 10 years of experience she has increasing risk of $\mathrm{SV}$.

We verified that the age of Nurses will affect SV. According Erikson, Grove (2008), age plays an important role in situations where they need to suppress or evoke 
Table 8 Statistical dependence according to workplace

\begin{tabular}{|c|c|c|c|c|}
\hline dimensions & $\chi_{\text {calc. }}{ }^{2}$ & $\mathbf{f}$ & $\chi_{\text {tab.0,05 }}$ & Evaluation \\
\hline EE & 9.736 & 2 & 5.991 & $\chi_{\text {vyp. }}^{2}>\chi_{\text {tab. } 0,05}^{2}$ \\
\hline DP & 4.549 & 2 & 5.991 & $\chi_{\text {vyp. }}^{2} \chi_{\text {tab. } 0,05}^{2}$ \\
\hline PA & 6.973 & 2 & 5.911 & $\chi_{\text {vyp. }}^{2}>\chi_{\text {tab. } 0,05}^{2}$ \\
\hline
\end{tabular}

Table 9 Comparison of Nurses by age

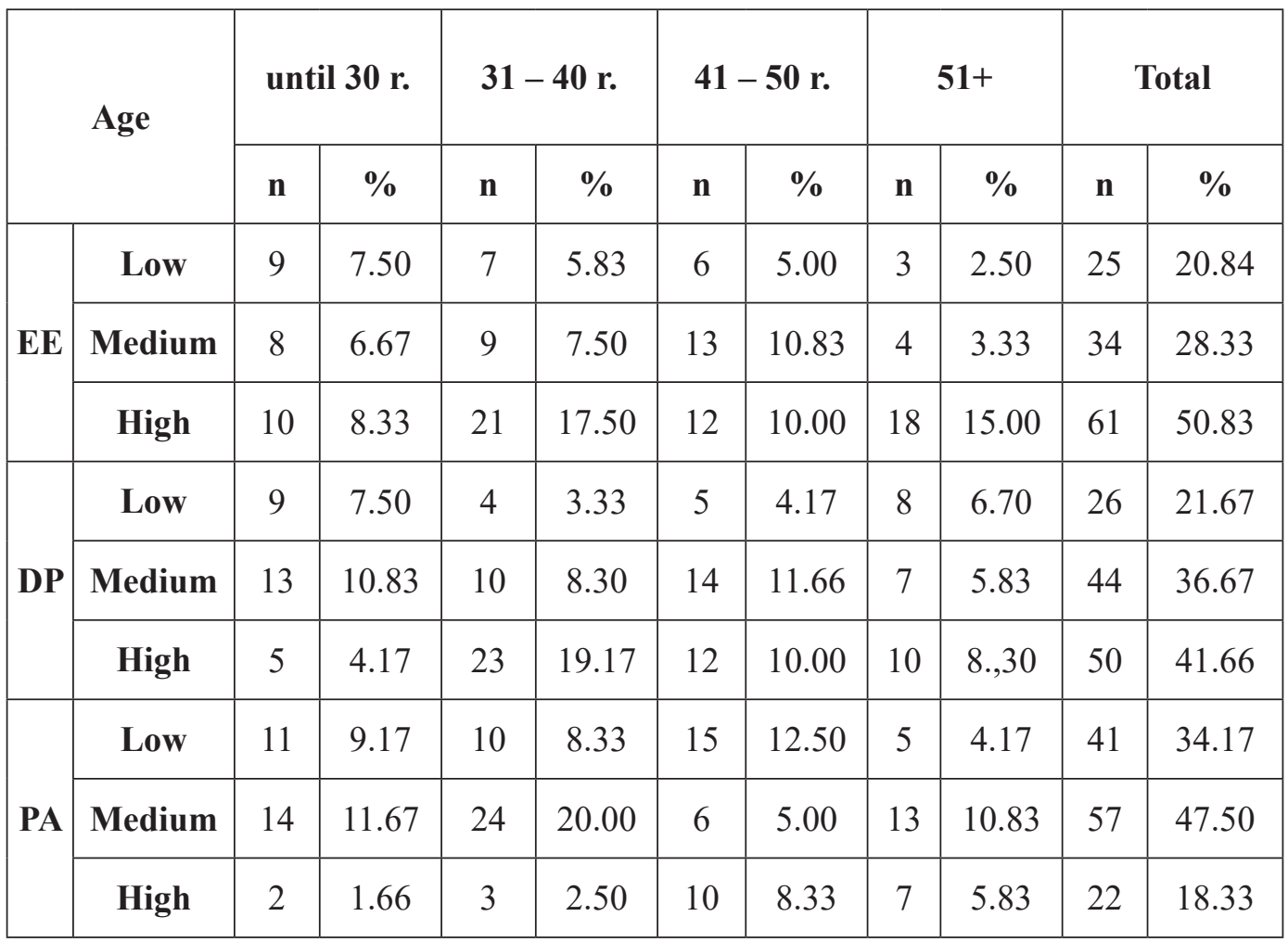

Table 10 Statistical differences according to age of Nurses

\begin{tabular}{|c|c|c|c|c|}
\hline dimension & $\chi^{{ }^{2} \text { vyp. }}$ & $\mathbf{f}$ & $\chi_{\text {tab.0,05 }}^{2}$ & Evaluation \\
\hline EE & 10.735 & 6 & 12.592 & $\chi_{\text {vyp. }}^{2}<\chi_{\text {tab. } 0.05}^{2}$ \\
\hline DP & 16.078 & 6 & 12.592 & $\chi_{\text {vyp. }}^{2} \chi_{\text {tab. } 0.05}^{2}$ \\
\hline PA & 18.808 & 6 & 12.592 & $\chi_{\text {vyp. }}^{2}>\chi_{\text {tab. } 0.05}^{2}$ \\
\hline
\end{tabular}


emotions that are appropriate to the situation. In our survey, the largest representation of Nurses were aged 31-40 years old $(30.83 \%)$. According to a study conducted on a sample of 843 Nurses in the United States, the age of Nurses has an effect on the formation of SV. In this study, Grove (2008) divided Nurses by age into two groups, before 30 and more than 30 years old. They focused on the survival of positive and negative emotions in relation to age and SV. They found that were no differences between age groups in experiencing positive emotion; among Nurses up to 30 years old significantly more experiences were reported such as frustration, agitation and anger, and therefore these Nurses burned out earlier than their older colleagues who are better able to manage their emotions.

The relationship between the age of Nurses (31-40) and dimension of emotional burnout is not confirmed; but the degree of depersonalization $(62.16 \%)$ and the degree of personal satisfaction $(64.86 \%)$ has been shown.

Confirmed was the relationship in the degree EE and age and the relationship and degree in age in $72 \%$ of Nurses over 51 years of age and degree of $52 \%$ for a younger age. Therefore, the older the nurse, the more the feeling of satisfaction from her work disappears. Of course, there are many external factors including the currently decreasing status of nursing in society and inadequate salary.

In our study, burnout in older Nurses can be compared with a study of Erikson and Grove (2008), which claims that by thirty years of service Nurses will experience burnout.

The result may be influenced by the different social status of Nurses abroad compared to the status of Nurses in our country. According Maslachova (in Kebza, Šolcová, 2003) in burnout syndrome, we are dealing with systemic rather then personal issues, and the occurrence of SV in an employee signals something that is not good, or does not work well in the organization. Therefore, we wanted to find out how to influence the employer toward prevention of the occurrence of SV on Nurses. Since the Labor Code obliges employers to provide employees working in the third risk group recovery stays or reduced working time, we wanted to find out whether this regulation is observed on Neurological and Oncological Departments as compared to working with carcinogenic substances according to law changing into a third risk group. Therefore, we considered recovery stays an important component in the prevention of the formation and development of SV. From n $=120$ of respondents (120) said that their employer provides recovery stays. Of these only $1.65 \%$ said that their employer offer recovery stays beyond the laws; $79.34 \%$ of respondents have reduced working hours and $76.86 \%$ reported supplemental leave.

For prevention, most Nurses $90.08 \%$ use various social activities; $82.65 \%$ seek recreational activities; $28.1 \%$ of Nurses engage in sports; $66.12 \%$ go to culture events such as cinema or theater. According Andrášiova (2006), important parts of preventing burnout are adequate and regular rest; ability to relax; purposefully eliminate stressors and raise salutors. Employers should provide psychological support programs for staff in hazardous work places that would allow health professionals to cope with their congested emotions; according to Andrášiova (2006)there is very low support in such work places and institutions. In statistical analysis, we confirmed the relationship between preventive measures and the rate of burnout in all three dimensions of the MBI Questionnaire.

\section{Conclusion}

We can say that the risk of burnout at different levels for Nurses not only will threaten but according to the research is already 
really present in this profession in all three dimensions.

In agreement with other authors, we affirm that Nurses in Neurological and Oncological Nursing have the highest rates of emotional burnout. An interesting finding was that even though we confirmed the relationship of age to the degree of burnout in depersonalization, personal satisfaction had no effect on burnout on an emotional level. Preventing burnout is not only an internal matter, but also has to be carried out at the level of organization to ensure balance between the level of competence, accountability and effective teamwork. We think that management is not aware of all the possibilities and forms of prevention that would be effective to protect against burnout. Therefore. in the future it would be appropriate to focus research on the possibility of preventative measures in relationship to burnout.

\section{References}

1. AGUAYO R, PECINO CV, DE LAFUENTE SOLANA EI, FERNÁNDEZ LML (2011). A meta-analytic reliability generalization study of the Maslach Burnout Inventory. Int $J$ Clin Health Psychol. 11(2): 343-361.

2. AIKEN LH, CLARKE SP, SLOANE DM, SOCHALSKI JA, BUSSE R, CLARKE H et al (2001). Nurses'reports On Hospital Care In Five Countries. In Health Aff. 20(3): 43-53.

3. ANDRÁŠIOVÁ M (2006). Burnout syndrome in medical practice, the possibilities for its management and prevention. In Viapractica. 3(12): 559-561.

4. ARONSON E \& LIDZEY G (1985). The Handbook of Social Psychology. New York: RandomHause, ISBN 0-7167-5715-X.

5. BAKKER AB, DEMEROUTI E, SCHAUFELI WB (2002). Validation of the Maslach Burnout Inventory -General Survey: An Internet Study across Occupations. Anxiety, Stress \& Coping. 15(4): 245-260.
6. BALBAY O A, ISIKHAN V, BALBAY EG, ANNAKKAYA AN, ARABAK PM (2011). Burnout status of health care personnel working in onkology and their coping methods. In HealthMED. 5(4): 730-740.

7. BARTOŠÍKOVÁ I (2006). The burnout syndrome for nurses. Brno: National Centre of Nursing and Other Health unions, ISBN 80-7013-439-9, 86 p.

8. CAMPBELL C \& ROTHMANN S (2005). A psychometric assessment of the Maslach Burnout Inventory (General Survey) in a customerservice environment. Management Dynamics. 14(2): 16-28.

9. CATALAN J, BURGESS A, PERGAMI A, HULME N, GAZZARD B, PHILLIPS R (1996). The psychological impact on staff of caring for peoplewith serious diseases: the case of HIV infection and oncology. $J$ Psychosom Res. 40(4): 425-435.

10. CÓRDOBA L, TAMAYO JA, GONZÁLEZ MA, MARTÍNEZ MI, ROSALES A, BARBATO SH (2011). Adaptation and validation of the Maslach Burnout Inventory-Human Services Survey in Cali, Columbia. Columbia Médica. 42(3): 286-293.

11. DIMUNOVÁ L \& NAGYOVÁ I (2012). The relationship between burnout syndrome and seniority among nurses and midwives in Slovakia. Profession on-line. 5(1): 1-4.

12. DYRBYE LN, THOMAS MR, MASSIE FS, POWER DV, EACKER A, HARPER $\mathrm{W}$, et al (2008). Burnout and suicidal ideation among U.S.medical students. Ann Intern Med. 149(5): 334-341.

13. EDELWICH J \& BRODSKY A (1980). Burn-Out: Stages of Disillusionment in the Helping Profesions. New York, NY: Human Sciences Press.

14. ELIÁŠOVÁ A (2001). Burnout syndrome. Health. 1(9): 38-41.

15. ERICKSON R \& GROVE W (2008). Why Emotions Matter:Age, agitation, and burnout among registered nurses. Online Journal of Issues in Nursing. 13(1). http://www. nursingworld.org/MainMenuCategories/ 
ANAMarketplace/ANAPeriodicals/OJIN/ TableofContents/vol132008/No1Jan08/ ArticlePreviousTopic/WhyEmotionsMatterAgeAgitationandBurnoutAmongRegisteredNurses.html.

16. FIGUEIREDO-FERRAZ H, GIL-MONTE PR, GRAU-ALBEROLA E (2013). Psychometric properties of the „Spanish Burnout Inventory" (SBI): Adaptation and validation in a Portuguese-speaking sample. Revue européenne de psychologie appliquée. 63(1): 33-40.

17. GIL-MONTE P (2005). Factorial validity of the Maslach Burnout Inventory (MBI-HSS) among Spanish professionals. Rev Saúde Pública. 39(1): 1-8.

18. GLOZIER N (2002). Mental ill health and fitnes for work. J Occup Environ Med. 59(10): 714-720.

19. HEFTYOVÁ E (2002). Threatens nurses burnout syndrome? Nurse. 1(2): 44-46.

20. HNÁTOVÁ I \& KOVALČÍKOVÁ N (2010). The issue of burnout in the provision of palliative care. Palliative medicine and pain treatment. 3(2): 57-58.

21. CHEN WS, HANIFF J, SIAU CH-S, SEET W, LOH S-F, JAMIL MHA (2014). Pilot Study of the Malay Maslach Burnout Inventory and Malay Work-Related Quality of Life Scale in Malaysia. Studies in Asian Social Science. 11: 20-26.

22. CHIRKOWSKA-SMOLAK $\mathrm{T} \&$ Kleka $P$ (2011). The Maslach Burnout Inventory-General Survey: validation across different occupational groups in Poland. Polish Psychological Bulletin. 42(2): 86-94.

23. CHRÁSKA M (2007). Methods of Educational Research. Praha: Grada, ISBN 97880-247-1369-4, 272 p.

24. IGLESIAS MEL, BECERRO DE BENGOA VALLEJO R, Salvadores Fuentes P. 2010. Reflections on the burnout syndrome and its impact on health care providers. Ann Afr Med. 9(4): 197-198.

25. KALLIATH, T, O`DRISCOLL MP, GILLESPIE DF, BLUEDORN AC (2000). A test of the Maslach Burnout Inventory in three samples of healthcare professionals. Work \& Stress. 14(1): 35-50.

26. KEBZA V \& ŠOLCOVÁ I (2003). Burnout syndrome. 2nd expanded and supplemented edition. Praha: State Health Institute, ISBN 80-7071-231-7, $25 \mathrm{p}$.

27. KLIMEKOVÁ A (2007),,,Burnout“" or where to share our elan vital. In Lichner J, Švanter P, editors. Military education. Bratislava: The personnel office OSSR, ISBN 978-80-969458-4-9, p. 92-105.

28. KMEŤ L' (2010). The possibilities of the prevention of burnout syndrome in the healthcare environment. In Selko D, Durka R, editors. The psychology of health. Bratislava: National institute of heart and vascular diseases, Bratislava, ISBN 978-80968092-6-4, p. 72-79.

29. KRAFT U (2006). Burned out: your job is extremely fulfilling. It is also extremely demanding - and you feel overwhelmed. You are not alone. Scientific American Mind. 17: 28-33.

30. LEITER MP \& SCHAUFELI WB (1996). Consistency of the burnout construct across occupations. Axiety Stress Coping. 12(9): 229-243.

31. MASLACH C \& JAKSON S (1981). The Maslach Burnout Inventory. Research ed. Palo Alto, CA: Consulting Psychologists Press.

32. MASLACH C \& JAKSON S (1986). The Maslach Burnout Inventory Manual. 2nd ed. Palo Alto, CA: Consulting Psychologists Press.

33. MASLACH C, JAKSON S, LEITER M (1996). The Maslach Burnout Inventory Manual. 3rd ed. Palo Alto, CA: Consulting Psychologists Press.

34. MESZÁROS V, ADÁM S, SZABÓ M, SZIGETI R, URBÁN R (2014). The Bifactor Model of the Maslach Burnout Inventory-Human Services Survey (MBI-HSS)-An Alternative Measurement Model of Burnout. Stress Health. 30(4): 82-88. 
35. PINES A, ARONSON E, KAFRY D (1981). Burnout: From Tedium to personal Growth. New York: Free Press.

36. Preventing and Reducing Burnout Among Staff Nurses: A Literature Review FS20101278. (2014). http://nursing.missouri.edu/ academics/master-of-science/pdf/msn exam_burnout. pdf.

37. ROTHMANN S \& MALAN H (2003). Koherensiesin, selfdoeltreffendheid, lokus van beheer en uitbranding by maatskaplike werkers. SA Journal of Industrial Psychology. 29(4): 43-51.

38. ROTHMANN S \& VUUREN JA (2002). Sence of Coherence, Self-Efficacy, Locus of control, Coping and Burnout of Senior managers in a Manufacturing Industry. Paper presented at the $1 *$ South African Burnout Conference, Potchefstroom.

39. SABBAH, I, SABBAH H, SABBAH S, AKOUM H, DROUBI N (2012). Burnout among Lebanese nurses: Psychometric properties of the Maslach Burnout Inventory-Human Services Survey (MBI-HSS). Health. 4(9): 644-652.
40. SARRO JC \& DENSTEN IL (1989). Undergraduate students stress and coping strategies. Higher Education Research \& Development. 8(1): 47-57.

41. SCHUTTE N, TOPPINEN S, KALIMO R, SCHAUFELI W (2000). The factorial validity of the Maslach Burnout Inventory General Survey (MBIGS) across occupational groups and nations. Journal of Occupational and Organizational Psychology. 73(1): 53-66.

42. SORKOVÁ T \& ZVARÍKOVÁ M (2003). Effective communication and coping with the workload in the teaching process. Vydavatel'stvo: Technical university, ISBN 97880-807-3015-4, $105 \mathrm{p}$.

43. VENGLÁŘOVÁ M et al (2011). Nurses in distress. Praha: Grada, 2011. ISBN 978-80247-3174-2, $192 \mathrm{p}$.

44. VORLÍČEK J, ABRAHÁMOVÁ J, VORLÍČKOVÁ H et al (2012). Clinical oncology for nurses. 2nd expanded and supplemented edition. Praha: Grada, ISBN 978-80-247-3742-3, $450 \mathrm{p}$. 